\title{
Design of an RFID-based Healthcare Management System using an Information System Design Theory
}

\author{
E. W. T. Ngai • J. K. L. Poon • F. F. C. Suk • C. C. Ng
}

Published online: 13 February 2009

(C) Springer Science + Business Media, LLC 2009

\begin{abstract}
This design science research study describes the design and development of a Radio Frequency Identification (RFID)-based Healthcare Management System (RHMS) for the healthcare industry. We examined the use of RFID technology as the key enabler for building the RHMS to deliver higher business values and provide effective support in transforming and optimizing healthcare practices in the industry. In this study, a prototype RHMS was built and implemented in a quasi-real world setting. The results validate the practical viability of the proposed system architecture. We show that the Information System Design Theory used to develop the RHMS could form the basis for further research. We hope the proposed system architecture and the developed prototype system from this study will help support and further the efforts of both academics and practitioners in RFID research.
\end{abstract}

Keywords Radio frequency identification (RFID) .

Healthcare Management System .

Information System Design Theory

E. W. T. Ngai $(\bowtie) \cdot$ F. F. C. Suk • C. C. Ng

Department of Management and Marketing,

The Hong Kong Polytechnic University,

Hung Hom,

Kowloon, Hong Kong

e-mail: mswtngai@polyu.edu.hk

J. K. L. Poon

Hong Kong Community College,

Kowloon, Hong Kong

\section{Introduction}

Healthcare is the world's largest industry (Janz et al. 2005), and its market size is growing continuously (Wilson and Lankton 2004). For example, in 2006 healthcare expenditure accounted for $16 \%$ of GDP in the United States, $10 \%$ in Germany, and $8 \%$ in Japan, and it is estimated to grow as high as $20 \%$ by 2020 (Jaffe et al. 2006). To cope with this expansion, the healthcare industry has been making major transformations in its information technology (IT) base (Wilson and Lankton 2004; Li et al. 2008) and calling for ways to utilize IT to deliver a higher business value and quality of care.

Radio frequency identification (RFID) is a recent innovative technology considered to be the next wave in the IT revolution (Tzeng et al. 2008; Umar 2005; Zang et al. 2008). Its emergence has dramatically affected a number of industries (Curtin et al. 2007; Ngai et al. 2008). It has been adopted in industries such as logistics (Ngai et al. 2007a, b), manufacturing (Swedberg 2006), food safety management (McMeekin et al. 2006; Kelepouris et al. 2007), and transportation (Caputo et al. 2003). Due to the relatively few academic publications are concerned with applying RFID in the healthcare industry, in this study we leverage its potential as a key enabler to examine how it might help to deliver higher business benefits and provide effective support for transforming healthcare practices. It is agreed that improved patient safety is the most important benefit of RFID.

Though healthcare is a growing industry, it faces many complex challenges in trying to deliver safe, cost-effective, and high-value healthcare (Wickramasinghe et al. 2005). Specifically, the following fundamental challenges in managing the operations and processes in some hospitals have been generally reported: 
Frequent cases of wrong medications given to patients Although health professionals have learned the importance of the "five rights" of safe medication use - the right patient, right drug, right dose, right route, and right timepharmaceutical-related errors occur frequently in hospitals. Six categories of the most prevalent medication errors have been commonly reported, namely, communication, poor drug distribution practices, dose miscalculations, drug device-related problems, incorrect drug administration, and lack of patient education (Wharton 2004). Beso et al. (2005) revealed that dispensing errors occurred in about $2 \%$ of all dispensed items, and about one in 100 of these were missed by the final check. Since dispensing errors can result in significant patient harm, we therefore need to design a system that focuses specifically on improving the pharmaceutical dispensing management in the healthcare system to help reduce potential dispensing errors and thus enhance patient safety.

Inefficient and inaccurate pharmaceutical inventory operations and controls In some hospitals, pharmaceutical inventories are still tracked with a great deal of manual operations and paperwork. For example, it is not uncommon for pharmacists to manually record the expiration date of drug items, monitor their restocking requirements, track the number of items used in a ward, and so forth. This makes pharmaceutical inventory operations and controls less efficient and accurate. What we need is automatic pharmaceutical inventory operations and controls to help maintain close monitoring and real-time reporting of inventory levels. In addition, effective removal of expiry and recalled drug products from the pharmaceutical shelf is essential.

Inadequate patient identification and location tracking processes When patients are admitted to a hospital, they are required to have wristband labels attached for identification purposes. Most hospitals have adopted barcode technology for their patient labels. However, using barcodes to identify patients has some limitations and weaknesses. For instance, occasionally it is necessary to read barcodes manually, and barcode readability can be poor in dimmed lighting environments (Kärkkäinen 2003). Because barcodes do not support passive patient identification, it is not feasible to track precise patient locations inside a hospital. Thus, we need to strengthen the patient identification process and its underlying technology.

In this study, we propose the architecture for an RFIDbased Healthcare Management System (RHMS) for the healthcare sector that will help strengthen the safety of patients and use of medication, improve pharmaceutical inventory operations and controls, and enhance patient identification and in-hospital location tracking processes.
The system architecture is generic in that it is relevant to a spectrum of different operating environments. The second phase of this study details the development of a prototype termed RHMS under the design science of information systems (IS) research guidelines. The prototype is an instantiation of the architecture and is tailored for healthcare applications. An empirical evaluation through the implementation of RHMS in a quasi-real world setting directly validated the prototype and in the process the key architectural features that address user flexibility and system dynamics.

The primary contributions of this research are two-fold. First, we present an illustrative example of the design and development of an RHMS in the form of an Information Systems Design Theory (ISDT) for a hospital. Second, we provide a theoretical contribution to guide developers and set an agenda for academic research.

The rest of the paper is organized as follows. In the next section, we present a brief overview of previous RFID applications. We then describe our design and development of an RHMS prototype of an ISDT. Next, we share some key issues related to implementing an RFID-based system in a hospital. Finally, we make some concluding remarks on the study and propose a research agenda.

\section{Previous RFID study in the healthcare industry}

RFID technology allows data to be wirelessly stored and automatically retrieved. It also provides a significant improvement over barcode technology in identifying, tracking, and stocking objects. RFID innovations have already been used in industries like logistics (Ngai et al. 2007a, b) and manufacturing (Swedberg 2006). Healthcare has been forecast to be the next home for RFID (Ericson 2004).

Østbye et al. (2003) evaluated an infrared/RFID equipment-tracking system in a tertiary care hospital to determine whether it could increase equipment utilization and appropriate charge capture and decrease personnel time spent looking for equipment. Once the system was made available, they observed increased use of infusion pumps but not of beds or sequential compression devices. Nursing staff and system users had positive impressions of the system and its potential. Thus, tracking systems can successfully locate hospital equipment and may improve utilization.

Cavalleri et al. (2004) presented a prototype of a wearable RFID device for automated staff and patient identification and tracking. They indicated that the RFID transponders (e.g., 13.56 Mhz and $125 \mathrm{Khz}$ tags) were low cost and easy to use; however, most were not feasible for 
adoption for in-hospital patient identification as the reader station unit produced significant amounts of electromagnetic energy not compliant with European standards for health care environments. Their prototype showed that its electromagnetic emissions were compliant with US and European standards, and it also tracked patients within a long-distance range of up to a few meters. Security features for the quality control of transmitted data and device authentication were also implemented.

Li et al. (2004) adopted RFID and mobile technology to implement a mobile healthcare service system for positioning and identifying persons and objects both inside and outside a hospital. The system demonstrated that a patient's location and bio-information could be collected using RFID devices that ubiquitously crossed geographic barriers. In particular, for a case of the sudden occurrence of any unknown epidemiology of disease, like the Severe Acute Respiratory Syndrome (SARS) in 2003, the system could effectively reduce the numbers of affected medical professionals and strengthen the infection control process among infectious patients.

Janz et al. (2005) demonstrated an RFID application used by the emergency department of a hospital. They reported that data collected from tagged patients could improve medical processes, decision making, and resource management. However, compared to their experience using RFID technology in the manufacturing and retail sectors, it was more challenging to develop an RFID-based application for tagging people in the healthcare environment since it involved patients, physicians, medical know-how and practices, and organizational issues.

Fisher and Monahan (2008) indicated that many hospitals have begun to adopt RFID applications to track inventory, identify patients, and manage personnel. In particular, RFID innovations have been used to track medical equipment to minimize search times, verify patient identification to avoid medical errors, and collect data on workflow to find inefficiencies in current hospital operations. However, they found that hospital staff, especially nurses, expressed concerns over the surveillance potential of these tracking technologies.

Despite the prior literature showing some signs of research and advancement in the study of RFID in the healthcare industry, there has been a lack of design science research into designing and developing an RFID system in general, and RHMS in particular. Because RFID is a developing technology, a good understanding of RFID system design and use is still emerging in both practice and academia (Ngai et al. 2007a, b). The plug-ins ready for use have not become commercially available. A more fundamental issue is the lack of a theory to guide design and development, since no investigation has been made into designing and developing one. The characteristics of
RHMS make it difficult to design and develop a system that currently has little theoretical guidance. Hence, there is a need to address this problem.

\section{A framework for designing and developing an RHMS}

Information Systems Design Theories (ISDTs), as defined by Walls et al. (1992), are prescriptive theories that integrate explanatory, predictive, and normative aspects into design paths and tells how a design process can be conducted in a more effective and feasible way. "The" nature of ISDTs is articulated using Dubin's concept of theory building and Simon's idea of a science of the "artificial" (Walls et al. 1992, p. 36). For practitioners, ISDTs are beneficial because they increase development reliability and the likelihood of success by providing principles and making the range of effective development practices more manageable (Markus et al. 2002). Therefore, an ISDT provides theory-based guidance on how to design and support a particular type of information system, which in this study is RHMS.

In the following section, we present the ISDT for RHMS by describing each of the four essential ISDT components as explicated by Walls et al. (1992), namely, kernel theories, meta-requirements, meta-design and design method.

\subsection{Kernel theories}

Kernel theory refers to theories from natural or social sciences governing design requirements (Walls et al. 1992). It could be an academic theory or a practitioner theory-in-use. Kernel theory enables formulation of empirically testable predictions relating the design theory to outcomes like systemrequirement fit (Markus et al. 2002). Developing an ISDT for RHMS requires a kernel theory to provide a basis for dealing with system development. In this study we have utilized the prototyping strategy as the basis for governing our design requirement. Prototyping strategy sets the platform to gather requirement or improves the system designs. It is a system development methodology that puts together a working model (i.e., a prototype) to test various aspects of a design, illustrates ideas or features, and gathers early user feedback from the evaluation.

Building a prototype system allows various issues to arise and be addressed. For instance, new concepts of user interface design can be evaluated. Prototypes can be used to clear up a variety of problems and learn about the concepts, framework, and design through the system-building process. The developers gain insights into the application area as well as the users' work tasks and the problems they face. 


\subsection{Meta-requirements}

Meta-requirements describe a class of goals to which the theory applies (Walls et al. 1992). Herbst and Karagiannis (2000) indicated that business-process knowledge could typically be acquired by interviewing personnel in the relevant business domain. We therefore conducted interviews with staff working in a hospital, with the aim of observing their operations at the same time. We visited two hospitals and interviewed 20 medical staff who held a variety of positions, ranging from medical consultants, physicians, registered nurses, and pharmacists to pharmaceutical procurement managers. These interviews enabled us to understand the current processes and operations in the healthcare environment. They also provided significant insights for us to re-think some existing healthcare practices that could be made more beneficial after business process re-engineering. Here we focus on several RFID-enabled processes as follows:

Patient identification process Patients in the hospital would be required to carry an RFID wristband that stores a patient's personal data such as a registration ID, name, age, admission date, medical history, and so forth. Nurses could use the handheld RFID readers with antennas to read the patient wristbands in order to accurately examine their identities, medical histories, doctor-in-charge, current drug charts and usages, and so forth. In an emergency, this piece of accurate patient information could help physicians and nurses make the decisions to give correct and responsive medications to save a patient's life.

Patient location tracking process After admission, every patient would be given an RFID wristband, which is an RFID transponder with an RFID tag embedded within. Patients' locations would be tracked by constantly reading the tag information from their wristbands using readers equipped with antennas, which would be placed at strategic locations inside the hospital. Even in a dimmed lighting environment, patients and those awaiting treatment in a large ward could be effectively located and identified.

Patient medication and monitoring process To reduce medication dispensing and usage errors, drugs would be tagged with RFID labels. Nurses could use handheld RFID readers to read the labels to examine medication details before dispensing to the patients. In addition, to improve the five "rights" of medication safety, patients' wristbands, which would contain the drug charts, medical history, last drug usage time, and the like, could be retrieved by the readers to further verify the medications matched to the patients. Once the drugs were taken, the patients' next medication details and drug charts would be updated onto their tagged wristbands. Readers with antennas located inside the hospital ward would regularly read the patients' wristbands to monitor whether the patients were closely following the instructions of the drug charts to receive the proper medication treatment. This kind of proactive and automatic medication usage monitoring process could enhance medication safety and ease nurse workload of manual monitoring.

Drug inventory management process To improve the efficiency and accuracy of drug inventory, an automatic process for tracking inventory levels as well as expired and recalled products would be feasible for drug products tagged with RFID labels. When drugs are moving in and out of the pharmacy dispensing room, the RFID readers would retrieve their quantities stored inside their tags and update their inventory levels into the system. Because RFID technology imposes a long read range without a specified sight requirement, pharmacists could be effectively alerted to expiry and recalled medication products inside the pharmacy room, which could be effectively identified and removed from the shelves. In this way, real-time reports of inventory levels could be achieved to enable responsive replenishment and reduce out-of-stock risks. Figure 1 shows an entity relationship (E-R) diagram of the system database schema, which specifies the relationships among the various entities.

Having learned about the business processes and operational environment in the healthcare industry, we then analyzed its business needs to define specific, unambiguous, and testable requirements. After discussing the business requirements with the key stakeholders, we summarized their key functional requirements for an RHMS. These requirements are shown in Table 1.

\subsection{Meta-design}

In this section, we design an artifact-an architecture framework of the RHMS which is generic and permits flexible modification. As shown in Fig. 2, the architecture framework of the RHMS is consisting of five layers: datacapturing front-end, data-capturing interface, processing modules, work-flow engine and application layer. The functions of each layer are described as follows:

\subsubsection{Layer 1: Data-capturing front-end system}

The first layer provides the RFID data-capturing front-end system. It contains three components: transponders, readers, and antennas. When patients are admitted to a hospital, they are required to carry a wristband (a transponder card). Each patient wristband is embedded with an RFID tag (dual dipole 


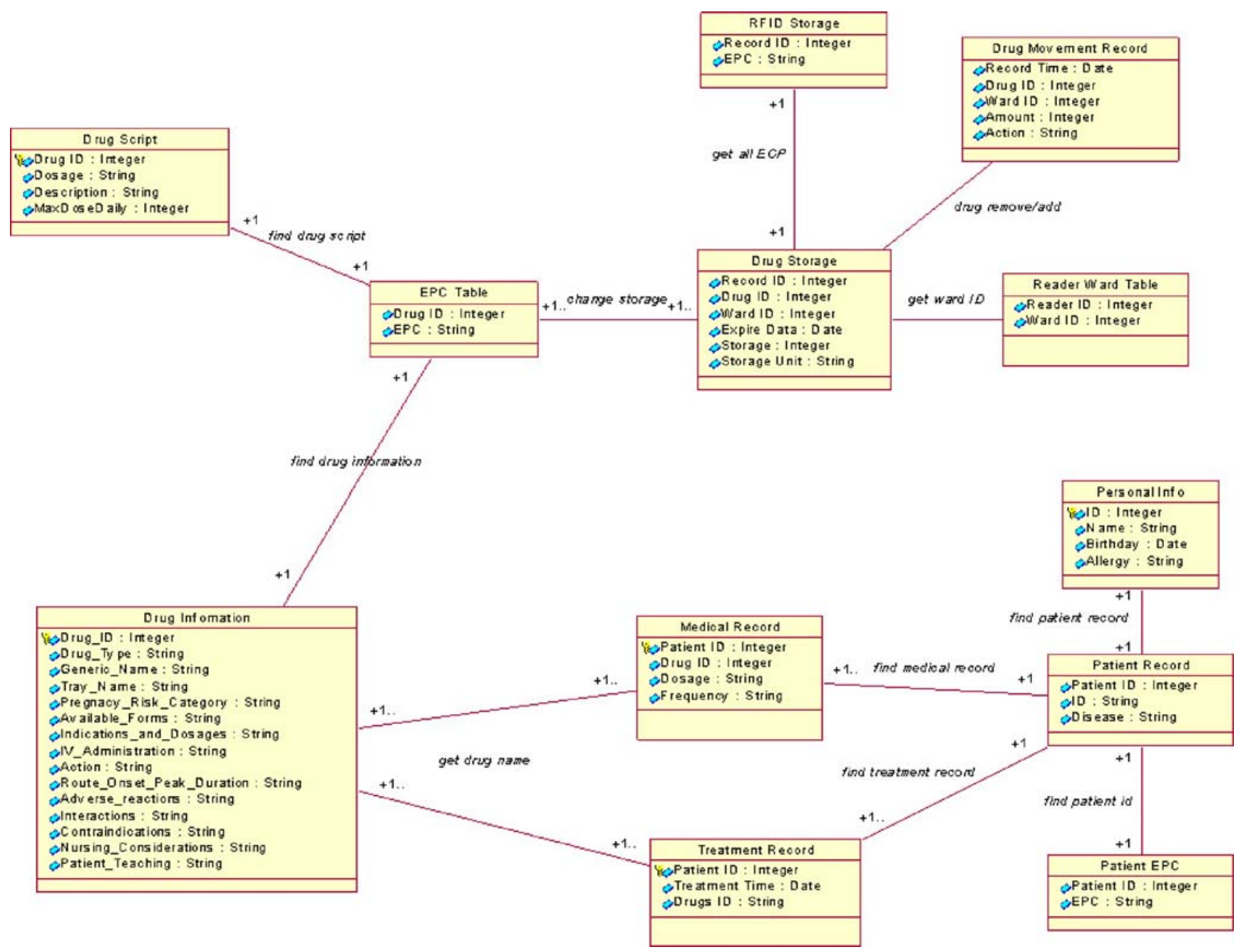

Fig. 1 E-R diagram of the RHMS

tag, which performs better in all orientations) that stores a patient's basic data such as registration ID, name, age, doctorin-charge, admission date, and so forth. Nurses can use the handheld readers to read the patient wristbands in order to accurately identify and match the right medications to the patients. To improve pharmaceutical inventory management, each pharmaceutical product is affixed with a transponder with an RFID tag inside containing the drug ID, name, expiry date, quantity, and the like. This arrangement allows automatic and real-time inventory level checking of the pharmaceutical products inside the pharmacy dispensing room. To effectively track the RFID tag information used throughout the hospital, including pharmaceutical inventories and patient locations, readers equipped with antennas are placed at strategic locations within the hospital to read or write necessary information onto the RFID tag. The tag information can thus be retrieved, updated, and processed by system components in the upper layers.

\subsubsection{Layer 2: Data-capturing interface}

Because the RFID tag and the in-house hospital system do not share the same data formats and standards, an interface is essential to enable communication between them. This interface converts the tag information into data that are readable in the system components in the upper levels, and vice versa.

\subsubsection{Layer 3: Processing modules}

The captured data are stored and managed by a set of relational databases. Specifically, four databases are designed for managing patient information, drug information, drug inventory management, and patient medication, respectively. These data repositories provide the essential information needed to drive the workflow engine to run various applications. Through the remote procedure call 
Table 1 Requirements for an RHMS by key stakeholders

\begin{tabular}{|c|c|}
\hline Stakeholders & Requirements for an RHMS in a hospital \\
\hline Patients & To provide high-quality care services \\
\hline \multirow{4}{*}{$\begin{array}{l}\text { Physicians \& } \\
\text { nurses }\end{array}$} & To provide an accurate way to identify patients \\
\hline & $\begin{array}{l}\text { To track precise patient locations throughout the } \\
\text { hospital }\end{array}$ \\
\hline & $\begin{array}{l}\text { To provide an effective way to strengthen the five } \\
\text { "rights" of medication safety }\end{array}$ \\
\hline & $\begin{array}{l}\text { To enable an automatic process to monitor usage of } \\
\text { patient medication }\end{array}$ \\
\hline \multirow[t]{4}{*}{ Pharmacists } & To automate pharmaceutical inventory tracking \\
\hline & $\begin{array}{l}\text { To facilitate locating and removing expiry and } \\
\text { recalled medication products from the inventory }\end{array}$ \\
\hline & $\begin{array}{l}\text { To provide real-time reports of medication inven- } \\
\text { tory levels }\end{array}$ \\
\hline & To reduce inventory costs and out-of-stock risks \\
\hline \multirow[t]{3}{*}{$\begin{array}{l}\text { Medical } \\
\text { executives }\end{array}$} & $\begin{array}{l}\text { To eliminate unnecessary manual processes and } \\
\text { operations }\end{array}$ \\
\hline & $\begin{array}{l}\text { To strengthen controls to improve patient and } \\
\text { medication safety }\end{array}$ \\
\hline & $\begin{array}{l}\text { To automate daily operations to lessen the workload } \\
\text { and pressure on hospital staff }\end{array}$ \\
\hline \multirow[t]{2}{*}{ System owner } & To provide user-friendly interfaces \\
\hline & $\begin{array}{l}\text { To provide accurate, easily accessed, and up-to-date } \\
\text { information like drug details and patient locations }\end{array}$ \\
\hline
\end{tabular}

utility provided by the relational databases, data in the relevant databases are extracted and updated by various applications in the upper levels. As information about patient and drug inventory is critical in a healthcare system, the databases are resided in the RAID disk system such that real-time data mirroring is performed to assure data integrity and persistence.

\subsubsection{Layer 4: Workflow engine}

This layer is used to manage, coordinate, and integrate the processes and flows of data between processing modules and application layers. A middleware interface is built for the applications to retrieve and update data from/to the respective databases in the processing modules. The middleware has defined a set of business rules and business logic that govern the proper flow of the data stream processed by various application systems.

\subsubsection{Layer 5: Application layer}

The application layer provides a user-friendly graphical interface for the hospital staff to use the application functions. Because the workflow engine has enabled a set of standard application program interfaces (API) that allow different applications and information systems to communicate effectively with one another, a new application like RHMS can be easily integrated with the existing legacy systems, such as the human resources management system, patient information system and the medicine treatment system, to achieve higher application interoperability.

System architecture development is the initial process of identifying the subsystems and establishing a framework among subsystem controls and communications (Sommerville 2007). The overview of system provides an encompassing and integrated environment for both logical design and physical implementation (Tung et al. 1992). The mapping between the system and business processes is used to guide application development and ensure proper integration. It defines the functionalities of the components and describes how they communicate with one another.

An overview of the RHMS is shown in Fig. 3. It has several key components: (i) the RFID reader, (ii) terminals, (iii) application and database servers, (iv) patient wristband, and (v) tagged drug items. All these components are linked up through a wireless network (WLAN).

We describe each of the key components below.

$R F I D$ reader RFID readers were placed at fixed positions inside the hospital and connected to several antennas to monitor patient drug usage, detect patient locations, and track pharmaceutical inventories.

Terminals Hospital staff could access the internal application systems through a user-friendly browser interface. Some terminals were equipped with handheld RFID readers that hospital staff could use to read and write tagging information from a patient's wristband or from drug items.

Application/database servers As a pilot, the application and database were placed in a single machine box. From an architectural perspective, they could be installed in separate machines. The application server contained web and Java containers from which web pages and Java-based programs could be run. The database server primarily included four relational databases: the patient information database, the drug information database, the drug inventory database, and the patient medication monitoring database. These databases were accessed through the Java Database Connectivity (JDBC) gateway to execute the queries.

Patient wristband The wristband was an RFID transponder with an RFID tag embedded inside. Every patient was given a wristband after admission. The wristband was used for identifying patients in the hospital. Some readers, which were equipped with antennas and placed at strategic locations inside the hospital, continuously read the tag information from the 
Fig. 2 Architectural framework of the RHMS

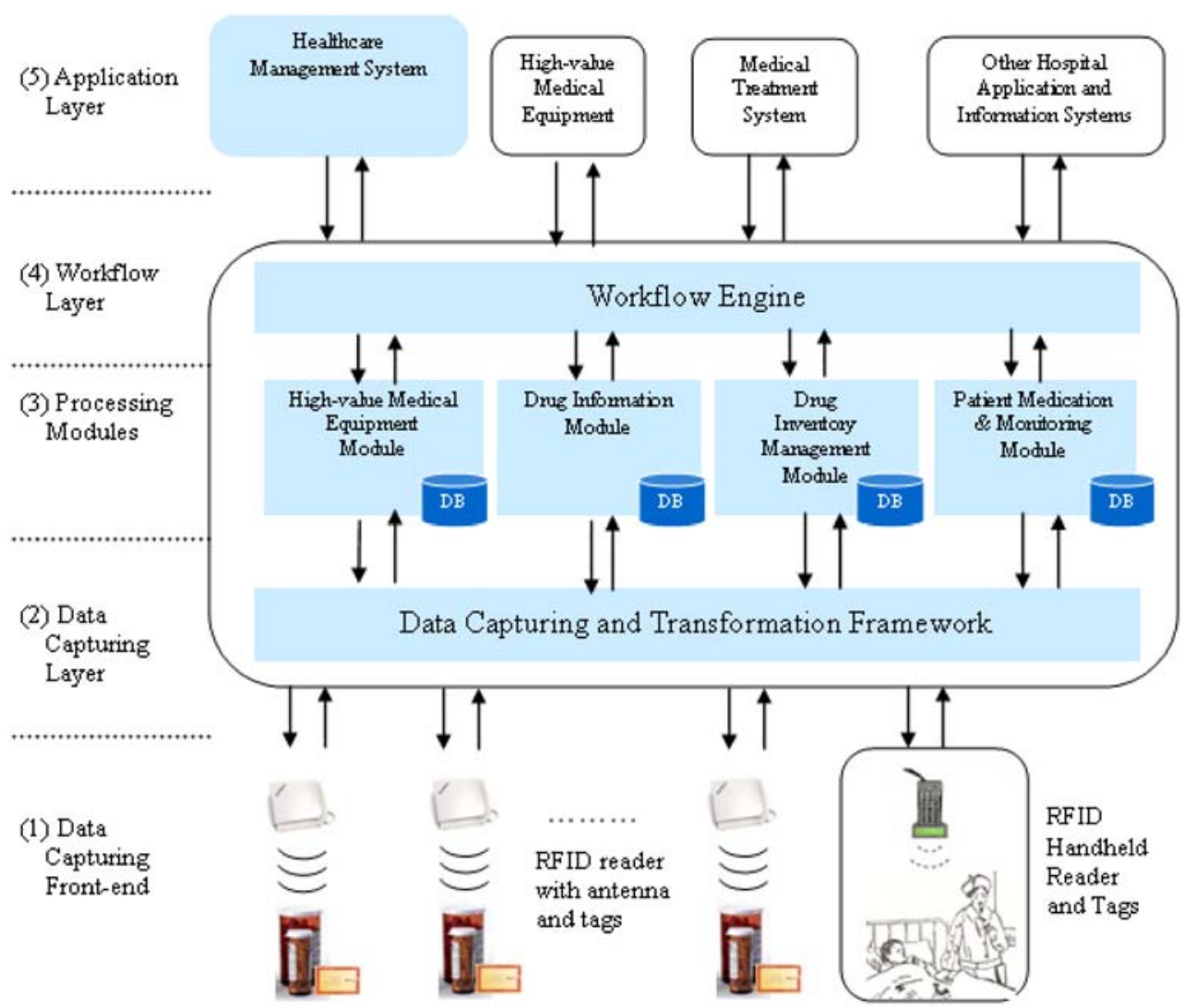

patients' wristbands to track their locations. The wristband also contained their medical histories, drug charts, doctor-incharge, and so forth. Nurses could examine patients' medical records before giving them medications.

Fig. 3 Overview of the RHMS
Tagged drug items A tiny RFID tagged label was embedded into each drug product item. The tag information could be either read or written by an RFID reader to retrieve and update a product's information such as quantity and

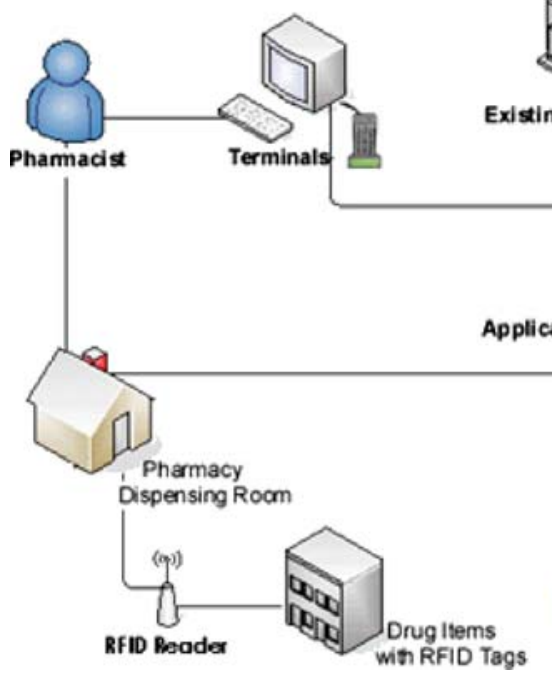

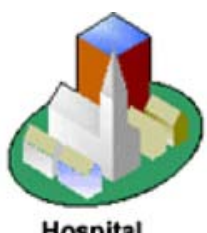

Hospital

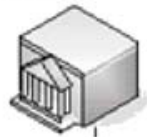

xisting Legacy Systems
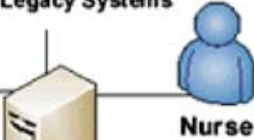

STS

DB servers
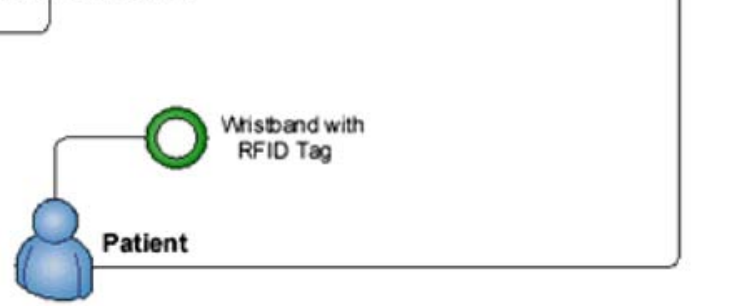
inventory levels when being moved into or out of the pharmacy dispensing room. These tagged items also facilitated automatic flagging for removing expiry and recalled product items from the inventory shelves.

\subsection{Design method}

Design method describes the procedures for artifact construction (Walls et al. 1992). Prototyping is a system development methodology that puts together a working model as a quick way to demonstrate a solution to a problem. In the system implementation stage, a prototype is built to test various aspects of a design, illustrate ideas or features, and gather early user feedback from the evaluation (Sommerville 2007). We developed the RHMS system according to our architectural and system design. HyperText Markup Language (HTML), JavaServer Pages (JSP) and Javascript, and Macromedia Flash programming languages were selected for developing the web-based interfaces, as they were portable and compatible with most web browsers. In addition, we used Java and Java Servlets for developing modules in the middle tier, such as session tracking and flow redirecting, because most current application servers like Tomcat widely support these kinds of Java components. Finally, a structured query language (SQL) was used for writing statements and queries in the relational database management system (RDBMS). The Java Database Connectivity (JDBC) protocol was selected for communication between the database server and the application server. Both SQL and ODBC are compatible with a variety of RDBMS databases.

Having developed the system prototype, we tested and evaluated it via systematic procedures. We performed a series of system tests, including module, integration, functionality and performance tests, to ensure that the prototype was free of bugs and errors. We further examined the prototype by inviting domain experts to evaluate it. Evaluations by domain experts help to determine the accuracy of embedded knowledge and the consistency and completeness of responses (Gasching et al. 1983).

We actively involved potential users throughout the ISDT process. Their feedback was obtained through different channels, including (i) interviews with different groups of potential users, (ii) comments elicited in informal meetings (iii) and user evaluations of the functional prototype system. User participation in different processes helped to enhance the usability, acceptability, usefulness and reliability of an RHMS in an earlier study (Lee and Girgensohn 2002). However, as RFID is a new technology in the healthcare sector, potential users may have difficulty visualising the work situations it would enable. Hence, we need to interpret their feedback with caution.
To obtain comprehensive feedback, we invited 45 potential users, including physicians, nurses, pharmacists and clerical officers to participate in an evaluation of the prototype system. During the evaluation session, we demonstrated the prototype and solicited feedback in the discussion and on an evaluation form. The results of the prototype evaluation were satisfactory and supported the contention that the RHMS system performed its functions as expected. The internal consistency reliabilities were tested and considered acceptable, as the Cronbach's coefficient alphas were higher than the alpha threshold level of 0.7 (Nunnally 1978).

A questionnaire that contained both closed and openended questions was also designed to collect users' views of the effectiveness and usability of the system prototype, and existing, established scales were used in the instrument. For the closed-end questions, potential users were asked to provide answers using a five-point scale $(1=$ strongly disagree, $3=$ undecided, and $5=$ strongly agree). The findings of the questionnaire were tabulated in Table 2. The results revealed that potential users in general gave high ratings on the effectiveness and usability of the system prototype, with a mean score of least 3.9 on a five-point scale. To ensure the values of our mean responses were statistically significantly different from " 3 " i.e. the neutral values of the scale ("undecided"), we have run one sample $t$-test using test value " 3 " on all questionnaire items. The

Table 2 Mean responses to the system evaluation by potential users $(n=45)$

\begin{tabular}{|c|c|c|}
\hline Question & $\begin{array}{l}\text { Mean } \\
\text { rating }^{\mathrm{a}}\end{array}$ & $\begin{array}{l}\text { Standard } \\
\text { deviation }\end{array}$ \\
\hline \multicolumn{3}{|l|}{ Effectiveness of the prototype RHMS } \\
\hline $\begin{array}{l}\text { 1. Helps in improving the pharmaceutical } \\
\text { dispensing management in the hospital }\end{array}$ & 4.0 & 0.6 \\
\hline $\begin{array}{l}\text { 2. Strengthens location tracking processes } \\
\text { in the hospital }\end{array}$ & 4.1 & 0.5 \\
\hline 3. Provides service quality in the hospital & 4.2 & 0.6 \\
\hline \multicolumn{3}{|l|}{ Acceptability of the prototype RHMS } \\
\hline 4. Prototype system is easy to use & 4.2 & 0.8 \\
\hline 5. Prototype system is user friendly & 3.9 & 0.6 \\
\hline $\begin{array}{l}\text { 6. Screen display of the prototype is well } \\
\text { designed }\end{array}$ & 3.9 & 0.7 \\
\hline 7. Achieves the stated objective & 3.9 & 0.8 \\
\hline $\begin{array}{l}\text { 8. Response time in the prototype system } \\
\text { is acceptable }\end{array}$ & 4.0 & 0.7 \\
\hline $\begin{array}{l}\text { 9. Prototype system contains functions } \\
\text { which user requires }\end{array}$ & 3.9 & 0.6 \\
\hline $\begin{array}{l}\text { 10. You can use the prototype system } \\
\text { without any difficulty }\end{array}$ & 4.0 & 0.6 \\
\hline $\begin{array}{l}\text { 11. Likely to recommend the prototype } \\
\text { system to other users }\end{array}$ & 4.1 & 0.8 \\
\hline
\end{tabular}

${ }^{\text {a }}$ Scale: 1 strongly disagree, 3 undecided, 5 strongly agree 
results show that the mean values of all questionnaire items were larger than 3.00 and significant at 5\% level. According to analyzed evaluation results described above, we regard the prototype as a promising system that could improve both the overall medical management and operational efficiency as required by the key stakeholders (see Table 1) in the healthcare sector.

\section{Implementation issues}

Our post-experimental interview with the nine domain experts and two RFID experts yielded several interesting perspectives on implementing the prototype. We describe some of the implementation issues below.

\subsection{Radio frequency site testing}

Because healthcare emphasizes maintaining a sterile and clean environment in a ward to avoid potential contamination, disruption of any wall or floor surfaces in the ward was not recommended. In addition, we assessed that the placement of the RFID readers would not affect the normal operations of the many types of electronic equipment inside the ward. We conducted an on-site test to ascertain the possible electromagnetic interference (EMI) of radio frequency solutions. Before developing the RHMS, we performed a survey to examine preparations on the hospital premises for deploying the RFID system, as well as pilot testing of the RFID tags, readers, and antennas. After the pilot run, we decided to use a dual dipole passive tag, which performs better in all orientations and to locate the readers above the doorways in the treatment and service areas of the ward. This placement proved to be the least disruptive and most accessible choice.

\subsection{Electromagnetic emissions in a healthcare environment}

Many European countries as well as the US have legislation and guidelines to ensure the safety of the healthcare environment, including the amount of electromagnetic energy emitted by in-hospital devices. Some RFID transponders (e.g., 13.56 MHz and $125 \mathrm{KHz}$ tags) were not permitted to be used inside a hospital as the reader station unit produced a significant amount of electromagnetic energy. Before implementing the RFID-based application inside a hospital setting, it is crucial that both medical and RFID experts be consulted to ascertain compliance with a specific country's safety standards for the healthcare environment.

\subsection{Leverage other enabling technologies}

To reduce overall implementation costs, it is recommended that other enabling technologies such as mobile technology, sensor technology, web services, and the like be leveraged. A holistic approach can optimize the internal rate of return (IRR) of the RFID investment.

\subsection{Complexity of integrating RFID with existing systems}

For maximum benefit, it is important to integrate RFID applications into the existing legacy systems. Because they do not share the same formats and standards, integrating RFID with existing hospital systems can be difficult. To cope with this issue, inter-operative or middle software can be embraced to increase system integration capability. In our proposed architecture design, we have adopted layered designs such that the data capture front-end and workflow interfaces, which are specifically designed to maximise compatibility between the new RFID solutions and the existing legacy systems of the hospitals.

\section{Contributions of the study}

We designed and developed an RHMS and evaluated it as a proof of the concept. The contributions of this research are two-fold in terms of the design artifact. First, we have presented the RHMS architecture, both in general terms and by focusing on the particular features that provide a rigorous level of system structure. Second, we have conducted an evaluation of the implemented system prototype. We invited 45 physicians, nurses, pharmacists and clerical officers to validate the practical viability of the proposed prototype architecture. The positive results gleaned from these participants provide evidence for the validation. However, an instantiation of the design artifact still needs to be evaluated in an operational RHMS environment and in other projects, as the findings of its use in a single project may not be generalizable to different environments (Markus et al. 2002). We believe that the RHMS will play an increasingly important role in the health care environment, particularly because health care practitioners can contribute to the activities involved in system evaluation. These contributions will advance our understanding of how to design and develop an RHMS in a hospital environment. We show that the ISDT used to develop the RHMS could help both practitioners and researchers. It offers theory-based guidance for the design and development of the RHMS to the former, whereas for the latter, it provides a basis for further research that will be subjected to theoretical and empirical validation.

\section{Future study}

This research should be followed up with a case study for two reasons (Benbasat et al. 1987). First, it would 
Fig. 4 Lookup for full drug detail information

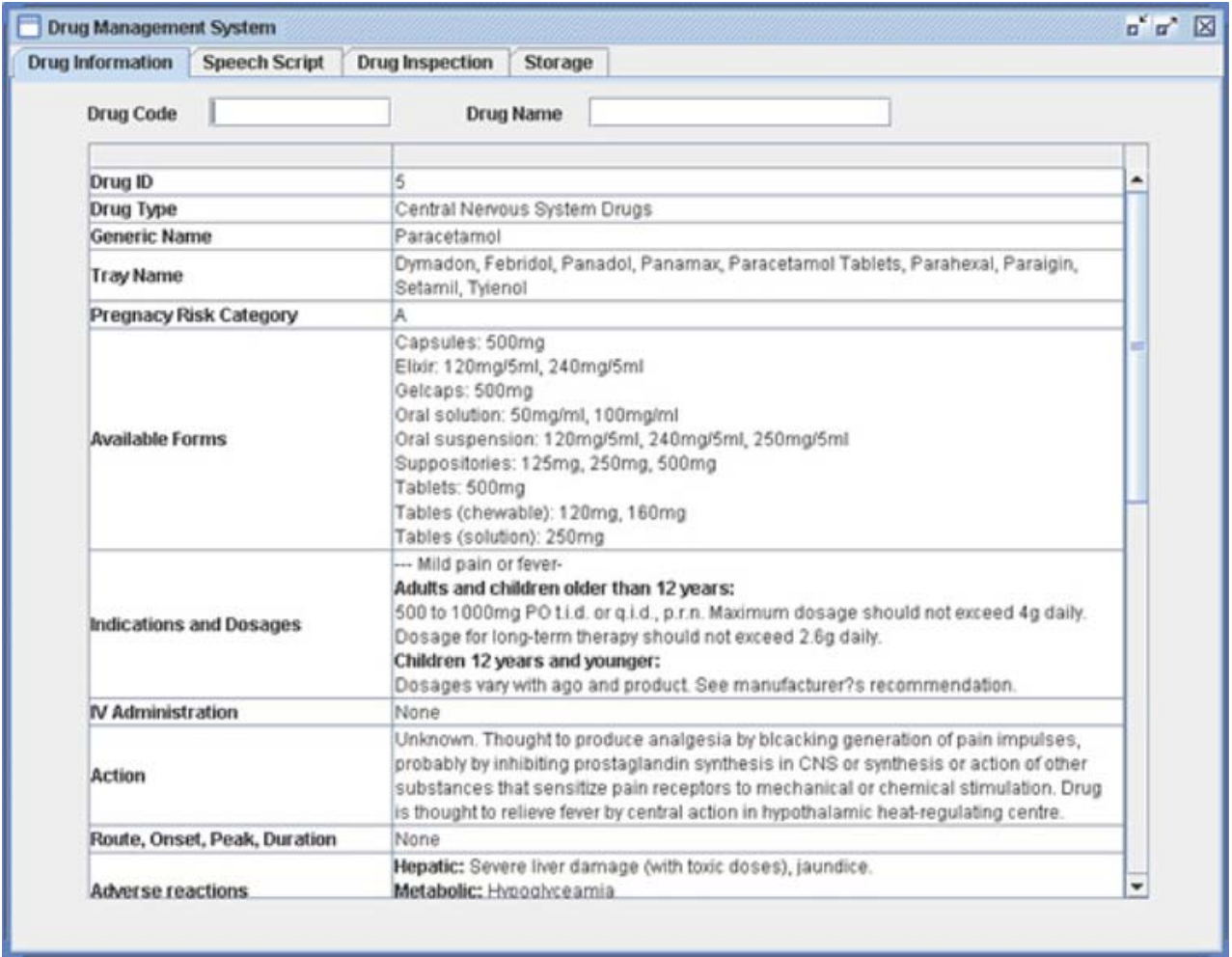

allow us to study the RHMS in a natural setting, learn about the state of the art and generate theories from practice. The healthcare operating environment is believed to be more turbulent and uncertain than that of other industries. Studying the proposed RHMS in a natural setting could help to validate the applicability of the system to environments that require greater flexibility, openness and customisation. Second, the case method

Fig. 5 Patient record

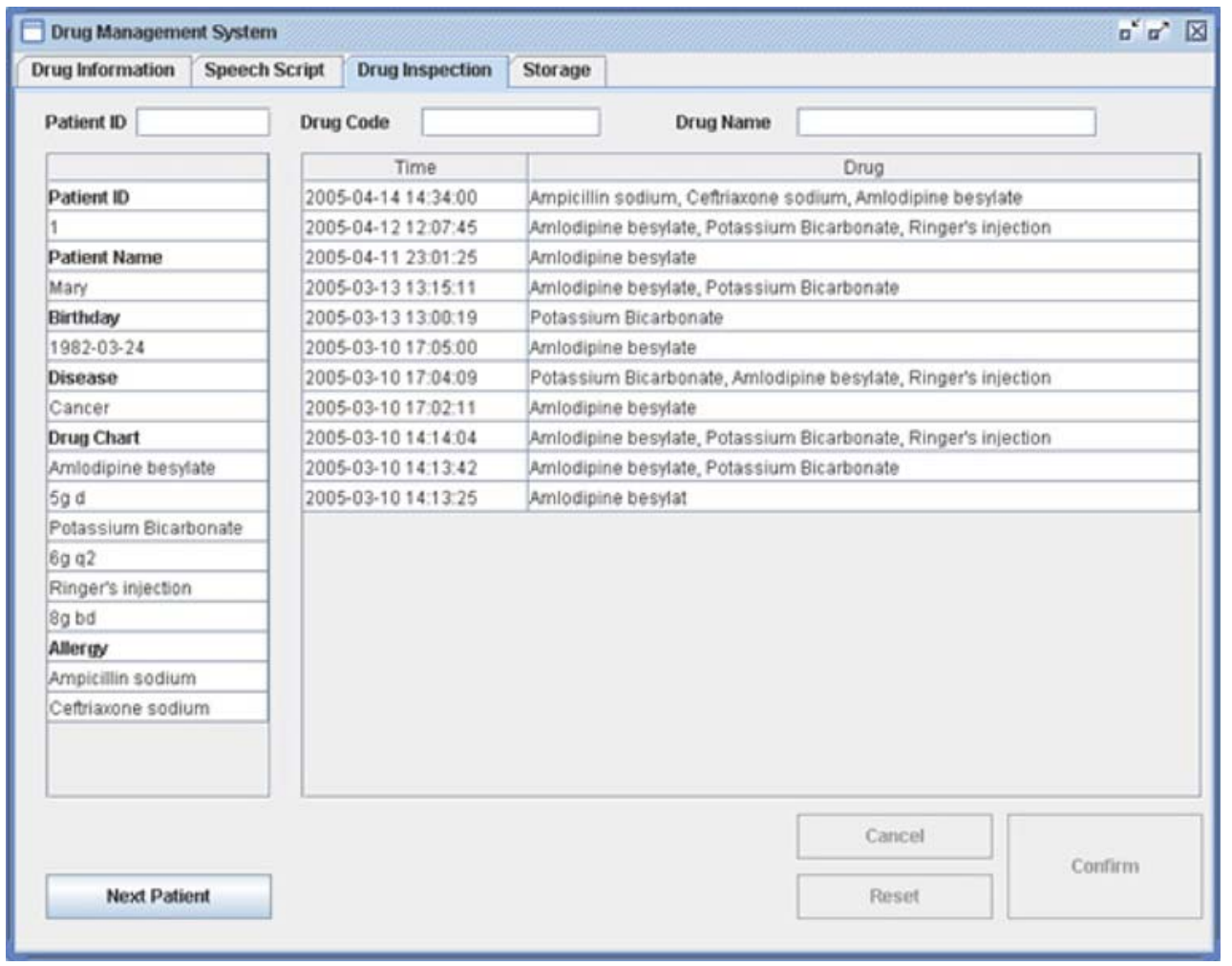


Fig. 6 Medication verification process

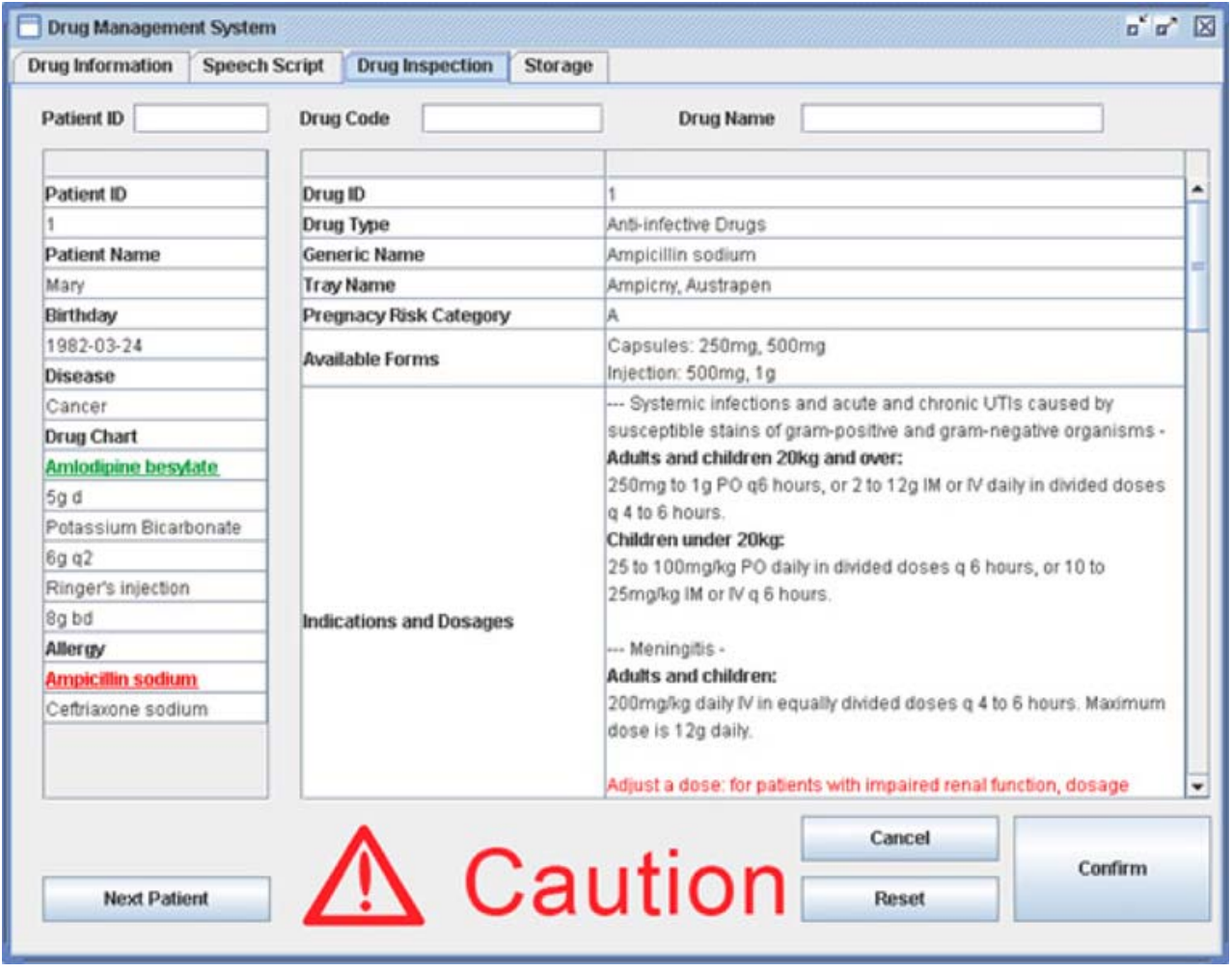

allows the researcher to understand the nature and complexity of the processes taking place.

There has been a lack of empirical studies on the use of RHMS in hospitals. We have demonstrated in this study that such a system can provide better service quality in a quasi-real world setting. Thus, it would be interesting in future research to conduct a field study that tests whether the RHMS improves the quality of the health care service
Fig. 7 Pharmaceutical inventory

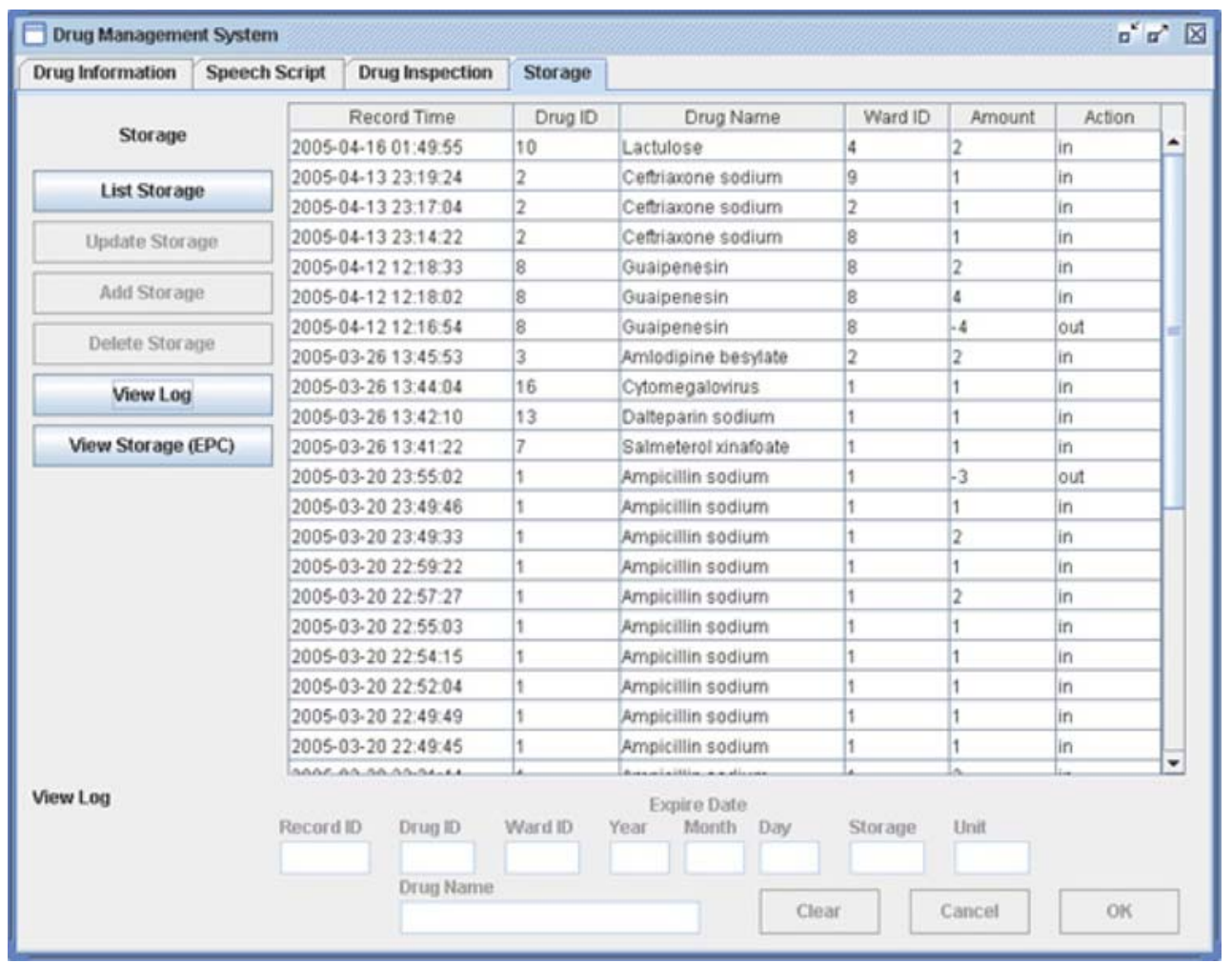


provided in a real hospital setting and investigate whether using the ISDT approach helps in the adoption of such a system. We propose the following hypotheses.

Hypothesis 1: There is no significant difference between the outcomes of service quality in hospitals that use RHMS and those that do not.

Hypothesis 2: The ISDT approach makes no significant difference in the level of RHMS adoption.

\section{Concluding remarks}

This paper presents an ISDT for the design and development of an RHMS prototype. We have evaluated it as a proof of the concept. The contributions of this research are the design artifact- the RHMS (the system architecture and its implemented prototype system). This system architecture has proved to be extremely useful in the development of an RFID-based application system in general and the RHMS in particular. We have described how the building of an artifact (i.e., RHMS development process knowledge) should be undertaken and what that artifact should look like once the RHMS has been built. This study also provides a theoretically grounded basis upon which future research about RFID systems implementation can be built. Drawing on principles from kernel theories of this ISDT, we have posed hypotheses that are open to empirical testing.

We have demonstrated a prototype system based on the proposed architecture and the ISDT approach. To validate the conceptual design of this prototype, we asked potential users to test and evaluate the system extensively to determine whether it could deliver significant results to strengthen the safety of patients and the use of medication, improve pharmaceutical inventory operation and control, and enhance patient identification and in-hospital locationtracking processes in the healthcare industry. This user evaluation demonstrated the practical viability of the proposed architecture. We believe the prototype developed using an ISDT approach will be useful and provide a workable means of helping hospitals to gain a better understanding of the design and development of the RHMS. We also discuss some of the key implementation issues related to an RFID-based application development. It is expected that a better understanding of the design and development of RFID systems in the healthcare industry will provide guidance for their successful implementation. We believe that RFID innovations will play an increasingly important role in this growing industry sector.

Acknowledgement This research was supported in part by The Hong Kong Polytechnic University under grant number ZZ73. The authors are grateful for the constructive comments of the three referees on an earlier version of this article. An earlier version of this paper was presented in the Pacific Asia Conference on Information Systems 2008.

\section{Appendix}

Illustrative examples of the system prototype

Looking at examples of the application of the system prototype is the best way to understand the RHMS. The examples given in this section are intended to provide a better understanding of the system. We demonstrate the primary capabilities of the system and show how it can help support the management of a hospital. Annotations are added to give an insight into the operation of the RHMS.

Figure 4 illustrates an example of the lookup for full drug details of "Paracetamol." After the reader detects the drug's RFID tag on the bottom of the Paracetamol, the system displays the full details of the drug information. The drug details are the same as those in the drug book.

Figure 5 shows a record of a patient when her wristband is read by a handheld RFID reader before being delivered medication by a nurse. The patient records include personal information, diseases, drug charts, allergies, treatment history, and so on. The nurse then uses the reader to verify that the medication contents are the right medication for the patient. As shown in Fig. 6, because there is a potential risk in delivering Ampicillin Sodium to the patient, the system will display an alert message to remind the nurse to further verify the medication.

Figure 7 illustrates a snapshot of a pharmaceutical inventory report in the dispensing room after the "List Storage" button is pressed.

\section{References}

Benbasat, I., Goldstein, D.K., \& Mead, M. (1987). The case research strategy in studies of information systems. MIS Quarterly, 3, $368-86$.

Beso, A., Franklin, B. D., \& Barber, N. (2005). The frequency and potential causes of dispensing errors in a hospital pharmacy. Pharmacy World \& Science, 27(3), 182-190.

Caputo, A., Pelagagge, P., \& Scacchia, F. (2003). Integrating transport systems in supply chain management software tools. Industrial Management \& Data Systems, 103(7), 503-515.

Cavalleri, M., Morstabilini, R., \& Reni, G. (2004). A wearable device for a fully automated in-hospital staff and patient identification. In: Proceedings of the 26th Annual International Conference of the IEEE EMBS, 3278-3281.

Curtin, J., Kauffman, R. J., \& Riggins, F. J. (2007). Making the "most" out of RFID technology: A research agenda for the study of the adoption, usage, and impact of RFID. Information Technology and Management, 8(2), 87-110. 
Ericson, J. (2004). RFID for hospital care. E-business Executive Daily. Fisher, J. A., \& Monahan, T. (2008). Tracking the social dimensions of RFID systems in hospitals. International Journal of Medical Informatics, 77, 176-183.

Gasching, J., Klahr, P., Pople, H., Shortliffe, E., \& Terry, A. (1983). Evaluation of expert systems: Issues and case studies. In F. Hayes-Roth, D. A. Waterman, \& D. B. Lenat (Eds.), Building expert systems pp. 241-280. Reading, MA: Addison-Wesley.

Herbst, J., \& Karagiannis, D. (2000). Integrating machine learning and workflow management to support acquisition and adaptation of workflow models. International Journal of Intelligence Systems in Accounting, Finance \& Management, 9, 67-92.

Jaffe, R., Nash, R. A., Ash, R., Schwartz, N., Corish, R., Born, T., \& Lazarus, H. (2006). Healthcare transparency: Opportunity or mirage. Journal of Management Development, 25, 981-995.

Janz, B. D., Pitts, M. G., \& Otondo, R. F. (2005). Information systems and health care II: Back to the future with RFID: Lessons learned-some old, some new. Communications of the Association for Information Systems, 15, 132-148.

Kärkkäinen, M. (2003). Increasing efficiency in the supply chain for short shelf life goods using RFID tagging. International Journal of Retail \& Distribution Management, 31(10), 529-536.

Lee, A., \& Girgensohn, A. (2002). Design, experiences and user preferences for a web-based awareness tool. International Journal of Human-Computer Studies, 56, 75-107.

Li, C. J., Liu, L., Chen, S. Z., Wu, C. C., Huang, C. H., \& Chen, X. M. (2004). Mobile healthcare service system using RFID. In: Proceedings of the 2004 IEEE, International Conference on Networking, Sensing \& Control, Taipei, Taiwan, 1014-1019.

Li, L., Xu, L., Jeng, H. A., Naik, D., Allen, T., \& Frontini, M. (2008). Creation of environmental health information system for public health service: A pilot study. Information Systems Frontiers, 10, 531-542.

Kelepouris, T., Pramatari, K., \& Doukidis, G. (2007). RFID-enabled traceability in the food supply chain. Industrial Management \& Data Systems, 107(2), 183-200.

Markus, M. L., Majchrzak, A., \& Gasser, L. (2002). A design theory for systems that support emergent knowledge processes. MIS Quarterly, 26(3), 179-212.

McMeekin, T. A., Baranyi, J., Bowman, J., Dalgaard, P., Kirk, M., Ross, T., Schmid, S., \& Zwietering, M. H. (2006). Information systems in food safety management. International Journal of Food Microbiology, 112, 181-194.

Ngai, E. W. T., Cheng, T. C. E., Au, S., \& Lai, K. H. (2007a). Mobile commerce integrated with RFID technology in a container depot. Decision Support Systems, 43, 62-76.

Ngai, E. W. T., Cheng, T. C. E., Kai, K. H., Chai, P. Y. F., Choi, Y. S., \& Sin, R. K. Y. (2007b). Development of an RFID-based traceability system: experiences and lessons learned from an aircraft engineering company. Production and Operations Management, 14(4), 554-568.

Ngai, E. W. T., Moon, K. K. L., Riggins, F. J., \& Yi, C. Y. (2008). RFID research: An academic literature review (1995-2005) and future research directions. International Journal of Production Economics, 112(2), 510-520.

Nunnally, Y. J. (1978). Psychometric theory. New York: McGraw Hill.

Østbye, T., Lobach, D. F., Cheesborough, D., Lee, A. M. M., Krause, K. M., Hasselblad, V., \& Bright, D. (2003). Evaluation of an infrared/radiofrequency equipment-tracking system in a tertiary care hospital. Journal of Medical Systems, 27(4), 367-380.
Sommerville, I. (2007). Software engineering (8th ed.). New York: Addison Wesley.

Swedberg, C. (2006). Crown saves manufacturing costs via RFID. RFID Journal. Retrieved November 10, 2006, from http:/www. rfidjournal.com/article/articleprint/2810/-1/1

Tung, S. L., Keim, R. T., \& Ramirez, R. G. (1992). Modelling the business via object-oriented techniques. System Sciences, IEEE Proceedings of the Twenty-Fifth Hawaii International Conference, 4, 557-567.

Tzeng, S. F., Chen, W. H., \& Pai, F. Y. (2008). Evaluating the business value of RFID: evidence from five case studies. International Journal of Production Economics, 112(2), 601-613.

Umar, A. (2005). IT infrastructure to enable next generation enterprises. Information Systems Frontiers, 7, 217-256.

Walls, J. G., Widmeyer, G. W., \& EI Sawy, O. A. (1992). Building an information system design theory for vigilant EIS. Information Systems Research, 3(1), 36-59.

Wharton, A. E. (2004). Oh no! Not another medication error!. Drug Topics, 48(22), 53-53.

Wickramasinghe, N. S., Fadlalla, A. M. A., Geisler, E., \& Schaffer, J. L. (2005). A framework for assessing e-health preparedness. International Journal of Electronic Healthcare, 1(3), 316-334.

Wilson, E. V., \& Lankton, N. K. (2004). Interdisciplinary research and publication opportunities in information systems and healthcare. Communications of the Association for Information Systems, 14, 332-343.

Zang, C., Fan, Y., \& Liu, R. (2008). Architecture, implementation and application of complex event processing in enterprise information systems based on RFID. Information Systems Frontiers, 10, 543-553.

Dr. E. W. T. Ngai is an Associate Professor in the Department of Management and Marketing at The Hong Kong Polytechnic University. His current research interests are in the areas of E-commerce, DSS and RFID applications. He has papers published in a number of international journals including MIS Quarterly, Journal of Operations Management, Decision Support Systems, IEEE Transactions on Systems, Man and Cybernetics, Information \& Management, Production \& Operations Management, and others. He serves on editorial board of six international journals. Dr Ngai has received the Faculty Award for Outstanding Performance/Achievement in Teaching (2003-2004).

Ms. J.K.L. Poon is a Lecturer in the Division of Business at Hong Kong Community College. Before becoming an academic, she had been working in the IT and telecommunication companies for more than 10 years. Her current research interests include knowledge management, management information systems and IT applications.

Dr. F. F. C. Suk is a Research Associate in the Department of Management and Marketing at The Hong Kong Polytechnic University. His current research interests are in the areas of E-commerce, RFID applications and IT management. He has been working in the banking and finance industry for more than 13 years.

Mr. C. C. Ng was a Double Degree student in the Department of Management and Marketing at The Hong Kong Polytechnic University. His current research interests are in the areas of electronic commerce, and RFID applications. 